\title{
Selecting the Startup Combined-cycle Power plants Initial Steam Temperatures in Compliance with the High-Pressure Steam Superheater Outlet Headers Heating Conditions
}

\author{
Yuri Radin \\ All-Russian Thermal Engineering Institute (VTI) \\ Moscow, Russian Federation \\ vti-unit@yandex.ru
}

\author{
Tatiana Kontorovich \\ All-Russian Thermal Engineering Institute (VTI) \\ Moscow, Russian Federation \\ kontorovich_ts@mail.ru
}

\begin{abstract}
This report represents heating/cooling conditions analysis of high-temperature details of the steam part equipment of combined-cycle power plants. The analysis is based on the justification of their cyclic strength by using 3D finite element models. A procedure is proposed which can be used to develop combined-cycle power plants startup assignment schedules for different initial thermal states and maintenance programs. The resulting solutions can be used to develop combined-cycle power plants diagnostic tasks.
\end{abstract}

Keywords-component; combined-cycle power plant; highpressure steam superheater; outlet header; initial difference of steam and metal temperatures; heating rate; startup; cyclic strength; startup assignment schedule; maintenance programs; diagnostic tasks

\section{INTRODUCTION}

Combined-cycle power plants (CCPPs), which owing to their high efficiency are designed to operate predominantly in base-load modes with a limited number of startupshutdown cycles (around 20-40 startups a year) are more and more frequently involved to participation in the control of power. According to the maneuverability requirements, the average number of CCPP startups must be around $330 \mathrm{a}$ year (10000 "startup-steady mode of operation-shutdown" cycles for 30 years of operation).

To prevent the occurrence of damage caused by high temperature stresses arising in thick-walled elements of boilers during CCPP startup and shutdown operations, the manuals for operating thermal power equipment and methodical guides prescribe the maximum permissible heating up-cooling down rates at which the number of "startup-steady mode of operation-shutdown" cycles complying with the maneuverability requirements is ensured during operation.

However, none of regulatory documents specifies the permissible values of initial steam temperatures depending on the initial temperature state of the outlet headers of steam superheaters used in the CCPP heat-recovery steam generators (HRSG), although it is exactly the initial difference between the temperatures of steam and metal that determines the possible maximum of stresses arising in the wall of a header as it is heated during the startup process.

It should also be pointed out that the outlet headers of high- and intermediate-pressure steam superheaters (for three-loop HRSGs with steam reheating), as well as the inlet headers of the HRSG economizer are the CCPP's critical elements that impose constraints on the rate of carrying out startup operations at the initial stages of the startup process [1].

\section{MAIN FACTORS DETERMING THE LONGEVITY OF THE OUTLET HEADERS IN HIGH-PRESSURE STEAM SUPERHEATERS}

The list of main factors affecting the stress-strain state of the header during the HRSG startup and shutdown processes includes the initial difference of temperatures between the steam and header wall, steam temperature variation rate, steam flow rate through the header, and internal pressure. In calculations of the headers, the stresses caused by the initial difference of temperatures and by the distribution of temperatures over the wall thickness resulting from convective heat transfer and internal pressure are summed. As a rule, only one or two of the above-mentioned factors play the determining role at different moments of the startup and shutdown processes. Thus, the difference between the temperatures of steam and header metal can play the key role initially in the startup process, especially if the boiler is started from cold and warm states, whereas steam flow-rate and pressure have a relatively small effect.

Initially in the startup process, a step like change occurs in the heating steam temperature with respect to the initial temperature of header metal, due to which a growth of stresses in it arises in the first minutes after admission of hot gases from the gas-turbine unit (GTU) into the HRSG [2]. At a small value of heat-transfer coefficient initially in the steam generation process in the HRSG (which corresponds to the GTU rotor idle running mode), this process is characterized by the difference of initial temperatures of gas and header metal $\Delta \theta=t_{\mathrm{g}}-t_{\mathrm{m}}$, which is due to a certain extent of redundancy in the steam superheater's tube system, as a result of which steam is rapidly heated to almost the temperature of gases at low steam flow rates.

A growth of stresses is accompanied by an increase of the header's outer surface heating rate. At the same values of maximal stresses, this rate is as a rule essentially higher than the heating rate connected with the growth of steam temperature during the load pickup process at high steam flow rates from the HRSG in the subsequent startup stages. 
The subsequent stages of the startup process involve long periods of time (up to 30-40 min) for which the system is held at a constant temperature of gases from the GTU and steam for preliminarily heating the steam lines and shells of the turbine's high-pressure stop valves, due to which relaxation of stresses occurs in the header's wall. With the steam temperature kept at a constant level for around 30-40 min in starting the HRSG from its cold state, the temperature stresses in the header decrease to almost zero. Another maximum of stresses arises as a result of heating the system at a constant temperature growth rate and with growing steam flow rates through the header in the course of increasing the HRSG steam output, which corresponds to a quasi-steady-state mode of operation. This maximum of stresses determines the header's cyclic strength during startups from hot and warm states when the initial temperature of metal exceeds the saturation temperature at the initial steam pressure in the HRSG high-pressure drum retained after its shut-down. This maximum of stresses determines the header's cyclic strength during cold startups, when its value exceeds the stresses due to the initial difference of temperatures between heating steam and metal (at high steam turbine loading rates).

As an example, Fig. 1 shows the change with time of the maximal equivalent stresses during the cold startup at the initial temperature of header's metal equal to $75^{\circ} \mathrm{C}$, initial steam temperature equal to $400^{\circ} \mathrm{C}$, and steam temperature growth rate equal to $30^{\circ} \mathrm{C} / \mathrm{min}$. The figure also shows the change with time of the main parameters, including steam temperature, GTU power output, and internal pressure, which have an effect on the calculation results. In parallel with carrying out the GTU shutdown operations, the steam turbine and the HRSG are cooled down during the GTU rundown process, followed by rotating its rotor by means of a turning gear. As a result, the process of cooling down the HRSG to its cold state takes 14-16 h after its shutdown. In accordance with the CCPP maneuverability requirements, the number of its cold startups for the entire service life totals 100 and that from warm state, 1900, the majority of which corresponds to cold startups. In view of the fact that during cold and warm startups the steam pressure in the boiler's high-pressure path is low (Fig. 2), the number of such startups may total up to 2000 for the entire service life [1].

Obtaining a shorter period of time taken to start a CCPP from its cold state is one of conditions it must comply with for being used in power control modes. This goal can be achieved by selecting the maximum permissible values of initial temperature and steam temperature growth rate at which the cyclic strength conditions are fulfilled. Figure 3 shows the

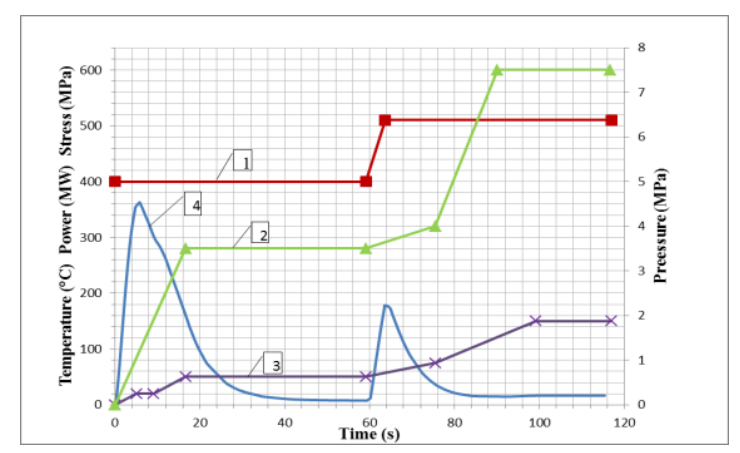

Figure 1. Cold startup of a 426x34 mm header. The initial header metal temperature is $75^{\circ} \mathrm{C}$, the initial steam temperature is $400^{\circ} \mathrm{C}$, and the steam temperature growth rate is $30^{\circ} \mathrm{C} / \mathrm{min}$. - Steam temperature, ${ }^{\circ} \mathrm{C} ; \times \mathrm{GTU}$ power output, $\mathrm{MW}$; - equivalent stresses, $\mathrm{MPa}$; and $\boldsymbol{\Delta}$ pressure, $\mathrm{MPa}$.

permissible number of cycles $\left[N^{*}\right]$ (cold startup- steadystate operation-shutdown) vs. initial steam temperature at different values of initial metal temperature for a header of size $426 \times 34 \mathrm{~mm}$ characteristic of a CCPP-450 combinedcycle plant. The behavior of the other parameters during the startup process is as shown in Fig. 1. Since the nominal steam temperature is equal to $510^{\circ} \mathrm{C}$, the effect of creep was taken into account in calculating the permissible number of cycles. Such dependences can be used for determining the initial steam temperature from the known temperature state of the header's metal and the permissible number of cycles $\left[N^{*}\right]_{\text {cld. }}$. The gas turbine's startup power output can be selected from the initial steam temperature (Fig. 4).

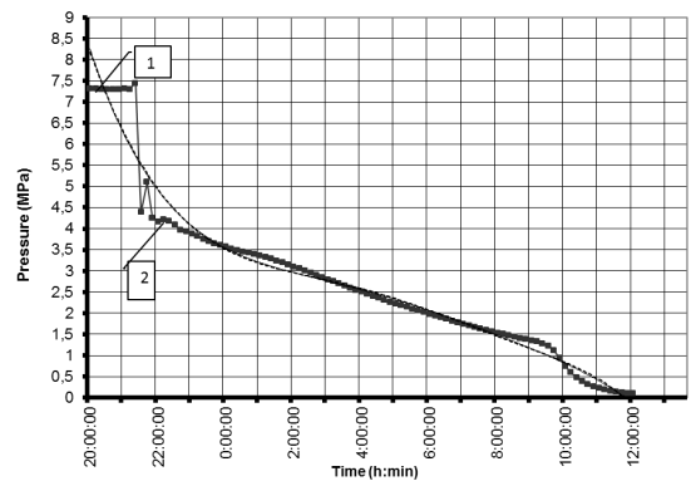

Figure 2. Pressure reduction in HRSG high-pressure drum during its cooling after shutdown of the CCPP-450T Unit No.1 at the Northwest Cogeneration Station on February 1, 2002. (1) Theoretical curve and (2) experimental curve obtained during tests.

\section{A PROCEDURE FOR ESTIMATING THERMALLY} STRESSED STATE AND CYCLIC LONGEVITY OF THE HEADERS USED IN HIGH-PRESSURE STEAM SUPERHEATERS

Knowing the required number of startups from different thermal states $N_{i}$, the parameters of nominal operating conditions, and calculated creep stress $\sigma_{\mathrm{cr}}$ for the nominal cycle temperatures at which creep is taken into account, it is possible to determine the design (permissible) number of startups of each type $\left[N^{*}\right]_{i}$ using the flaw summation principle [3]: 


$$
\begin{aligned}
& \sum N_{\mathrm{i}} /[N]_{\mathrm{i}}+\left(1.25 \sigma_{\mathrm{c}} / \sigma_{\tau / \mathrm{t}}\right)^{\mathrm{m}} \leq D_{c}, \\
& \sum N_{c l d} \mathrm{n}_{\mathrm{i}} /\left[N^{*}\right]_{i} \leq 1,
\end{aligned}
$$

where $N_{i}$ is the number of startups of the $i$ th type; $D_{\mathrm{c}}$ is the parameter characterizing the permissible damage under the combined effect of fatigue and creep; $\sigma_{\tau / t}$ is the conventional long-term tensile strength, $\mathrm{MPa}$ (in accordance with [3], we can take $\sigma_{\tau / t}=1.5[\sigma] ;[\sigma]$ is the nominal permissible stress; $m$ is the exponent in the long-term strength equation; $N_{\text {cld }}$ is the required number of cold startups; $n_{i}$ is the ratio of the number of $i$ th-type startups to the number of cold startups; $[N]_{i}$ is the permissible number of loading cycles according to the design low-cycle fatigue curves; and $\left[N^{*}\right]_{i}$ is the permissible number of cycles determined from the formula

$$
\left[\mathrm{N}^{*}\right]_{\mathrm{i}}=[\mathrm{N}]_{\mathrm{i}} /\left\{\mathrm{D}_{\mathrm{c}}-\left(1.25 \sigma_{\mathrm{c}} / \sigma_{\mathrm{t} / \mathrm{t}}\right)^{\mathrm{m}}\right\}
$$

We can show, taking the header of size $426 \times 34 \mathrm{~mm}$ as an example, how the initial heating steam temperature (from which the gas turbine's initial power output can subsequently be selected) can be determined by using the dependences for cold startup shown in Figs. 3 and 4. To do so, the permissible number of cycles for cold startups $\left[N^{*}\right]_{\text {cld }}$ corresponding to the assumed heating steam temperature is established in accordance with Fig. 3, and the ratio $N_{\text {cld }} /\left[N^{*}\right]_{\text {cld }}$ is calculated. From Eq. (1), the ratio $N_{\text {hot }} /\left[N^{*}\right] \leq$ $1-N_{\mathrm{cld}} /\left[N^{*}\right]_{\mathrm{cld}}$ for hot startups is determined, from which the permissible number of cycles $\left[N^{*}\right]_{\text {hot }}$ is determined for the known number of hot startups $N_{\text {hot }}$. If the maximal value of stresses during a hot startup (which determines the header's cyclic strength) is caused by the difference between the initial temperatures of steam and metal, the initial steam temperature at which the permissible number of cycles $\left[N^{*}\right]_{\text {hot }}$ is ensured can be selected proceeding from the known initial temperature of metal using a graph similar to that shown in Fig. 3 but constructed for hot startups.

Calculations aimed at analyzing stress-strain state of the header were carried out on 3D mathematical models by means of the ANSYS software system (license No. 663086 issued on April 16, 2012), which allows solid body heat transfer and mechanical problems to be solved simultaneously using the finite-element method.

After finishing the preliminary heating process and admitting steam to the turbine, the startup stage is performed at a constant steam temperature buildup rate and is simulated by quasi steady-state heating with the initial value of header

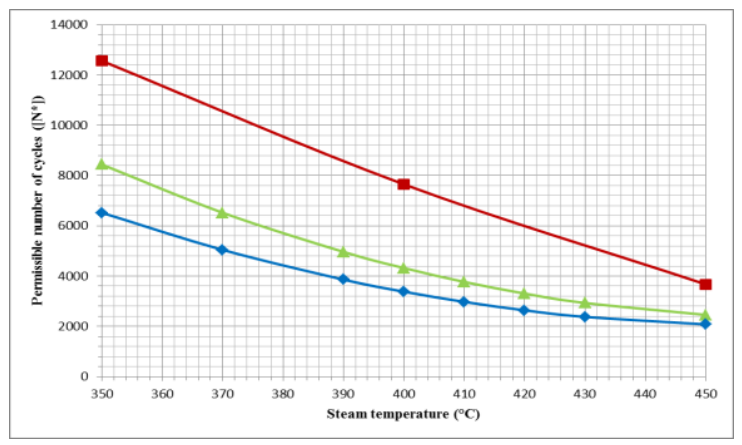

Figure 3. Figure 3. Permissible number of cycles [N*] (cold startup performed at a constant steam temperature buildup rate and is simulated by quasi steady-state heating with the steady-state operation-shutdown) vs. the initial steam temperature at different values of initial metal temperature t0 of a 426 x 34mm header t0, ${ }^{\circ} \mathrm{C}: \mathbf{-} \_-150 ; \mathbf{\Delta}-100 ; \bullet-75$.

metal temperature corresponding to completion of the first startup stage.

Fig. 5 shows the dependences of the permissible number of cycles (determined according to low-cycle fatigue curves) $[N]$ on the header's outer surface heating (cooling) rate under quasi steady-state conditions constructed from an analysis of the "startup-steady-state mode-shutdown" cycle under the following conditions: the initial steam temperature is equal to the initial temperature of metal $\left(300^{\circ} \mathrm{C}\right)$ (this can be regarded as simulation of a hot startup); the steam temperature variation rates have different values in the course of heating and cooling; and the heat transfer coefficient is taken equal to

$1500 \mathrm{~W} /\left(\mathrm{m}^{2} \mathrm{~K}\right)$, which corresponds to the average value of heat transfer coefficient calculated from the nominal parameters of steam from the HRSG for the outlet headers of the high-pressure steam superheaters used in the CCPPs operating in the Russian Federation.

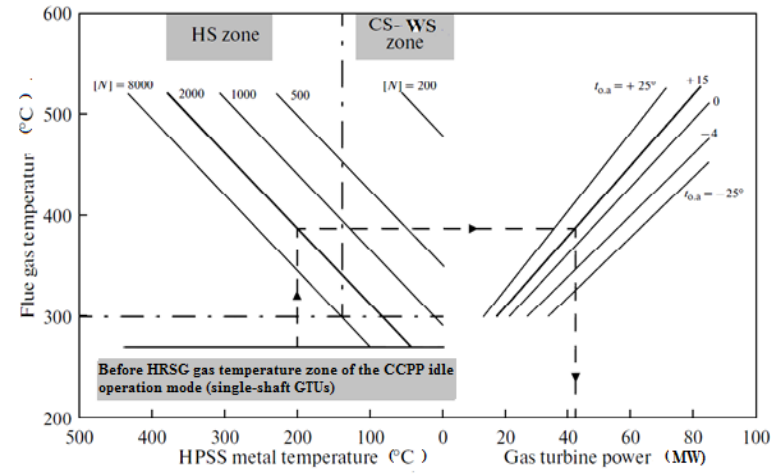

Figure 4. Nomographic for determining the gas turbine initial load as a function of the temperature of high-pressure steam superheater (HPSS) metal (a 426 x 34 header) for CCPP-450T power unit at the Northwest cogeneration station. The initial value of heat-transfer coefficient is 500 $\mathrm{W} /\left(\mathrm{m} 2^{\circ} \mathrm{C}\right)$ 


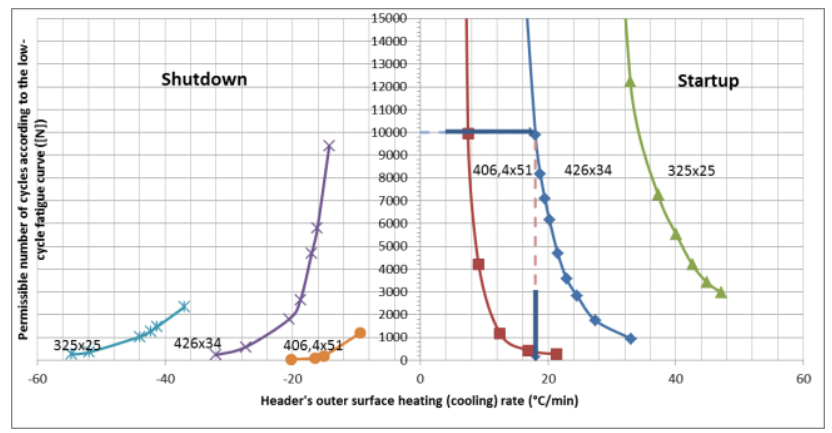

Figure 5. Results from calculation of the headers for low-cycle fatigue. The initial metal temperature $\mathrm{t} 0=300^{\circ} \mathrm{C}$; the heating-cooling rates are constant with time.

The results obtained from calculations of the stressstrain state of the header were used for estimating its cyclic strength. In accordance with [3], low-cyclic fatigue strength was calculated using the theory of maximal tangential stresses by analyzing the equivalent stresses defined as the algebraic difference of the main normal stresses

$\sigma_{i j}=\sigma_{i}-\sigma_{j}(i, j=1, \ldots, 3)$.

The nowadays approaches to determining the permissible heating rates were derived from the condition according to which the required service life of equipment operating at varying temperatures is ensured if the total stress at its concentration spot does not exceed the permissible value. The yield strength $\sigma_{y}$ or long-term strength is taken as the permissible strength. The basic assumption here is that at temperatures exceeding 450$500^{\circ} \mathrm{C}$ the total duration of test rather than the number of loading cycles plays the determining role. If we take the safety margins in accordance with [3], i.e., $n=1.5$, then, generalizing these two approaches, we can write the strength condition as follows:

$\sigma_{i} \leq[\sigma]$,

where $\sigma_{i}$ is the stress intensity, MPa; $[\sigma]=\min \left\{\sigma_{\mathrm{u}} / 2.4, \sigma_{0.2 / \mathrm{t}} / 1.5, \sigma_{2 \times 10}{ }^{5} / \mathrm{t} / 1.5\right\} \quad$ is the nominal permissible strength that does not depend on the design life or corresponds to the design life equal to $2 \times 10^{5} \mathrm{~h} ; \sigma_{\mathrm{u}}$ is the ultimate tensile strength; $\sigma_{0.2 / t}$ is the conventional yield limit; and $\sigma_{2 \times 10} / \mathrm{t}$ is the conventional long-term strength.

Methods for substantiating the required service life of power equipment are also known that are based on the assumption according to which the stress variation amplitude in a "startup-steady-state operation-shut- down" cycle at stress concentration spots must not exceed the permissible values determined by the joint effect of cyclic and static loads. Such an approach has been implemented in the international regulatory documents European Norm 12952-3 and TRD-301 [4]; however, the recommendations on selecting the permissible heating rates that are presently in force in the Russian Federation do not take this approach into account.
The results obtained from the performed calculations allowed us to establish the dependence between the outer surface heating rate and low-cycle fatigue strength for the outlet headers in the steam superheaters of two-and threeloop HRSGs used in CCPPs of different standard sizes. In calculating stresses taking creep into account, we considered all kinds of static loads experienced by the headers in the course of their operation: internal pressure, selfcompensation stresses, and mass loads.

The results from the calculated and experimental studies carried out at the All-Russian Thermal Engineering Institute have shown that the stresses due to self-compensation of temperature expansions do not exceed the stresses caused by internal pressure; therefore, the resulting axial stresses were calculated taking into account self-compensation stresses, which were taken equal to the stresses caused by internal pressure. The stresses due to internal pressure were calculated using the formulas from [3] taking into account the recommended value of stress concentration factor equal to 3 .

\section{CONSTRUCTION OF ASSIGNMENT SCHEDULES AND SELECTION OF THE INITIAL POWER OUTPUT}

The proposed approach to analyzing the thermally stressed state of headers and steam lines can be used in constructing assignment schedules. In this case, the problem of optimizing the CCPP startup modes is regarded as the problem of constructing startup assignment schedules in accordance with the technological requirements, the fulfilling of which will keep the limiting indicators at a level close to the maximum permissible value, at which the minimal startup time is achieved.

The procedure of constructing assignment schedules using the dependences presented above can be regarded to consist of the following stages.

(1) The initial steam flow rate and the coefficient of heat transfer from steam to header metal are determined.

(2) The temperature of flue gases and the gas turbine initial load are selected depending on the initial temperature of the high-pressure steam superheater's metal.

At the initial stage of the startup process, during which the steam flow rate has low values, the selection of initial steam temperature in fact corresponds to selection of flue gas temperature and, accordingly, the gas turbine initial power output. The nomographic chart in Fig. 4 shows how the initial (startup) load of the CCPP-450T combined-cycle plants is selected from the initial metal temperature of the high-pressure steam superheater's header having a size of $426 \times 34 \mathrm{~mm}$ with the initial heat-transfer coefficient equal to $500 \mathrm{~W} /(\mathrm{m} 2 \mathrm{~K})$. The first quadrant contains the permissible number of cycles according to the initial stepped change of temperature at a preset metal temperature of the high-pressure header with a size of $426 \times 34 \mathrm{~mm}$. Depending on the initial temperature of the high-pressure steam superherater's metal, zones of starting from hot, cold, and warm states are separated. The second quadrant contains the flue gas temperature according to the gas turbine power output. 
Increasing the steam flow rate and temperature, the permissible growth rate of steam temperature is determined using the methods and dependences presented above, and its value is compared with the actual temperature growth rates.

\section{CONCLUSIONS}

1) The steam superheater's outlet header is one of the heat-recovery steam generator's main critical components determining the duration of all types of the CCPP startup process. In some types of startups, especially from cold state, the initial difference between the temperatures of steam and header metal is the key factor influencing the headers' cyclic strength; the existing operational regulations impose no limitations on this parameter.

2) The calculations carried out on a 3D mathematical model of the header have shown that its thermally stressed state during startups at the preset values of steam flow rate and initial temperature of header's metal is governed by the ratio between the initial difference of the steam and header metal temperatures and the steam temperature growth rate in the subsequent stages of the startup process.

3) Dependences have been proposed using which it is possible to select the initial steam temperature from the known temperature of metal at which the required number of "startup-steady-state operation- shutdown" cycles is ensured for the cases in which the cyclic strength of the header is governed by the initial difference between the temperatures of steam and header metal.

4) Nomographic charts have been proposed for determining the permissible steam temperature growth rates at which the required cyclic strength is ensured.

\section{REFERENCES}

[1] A. F. Bogachev, Yu. A. Radin and O. B Gerasimenko, "Operational Peculiarities and Damageability of the Heat-Recovery Steam Generators Used in Binary Combined-Cycle Plants," Energoatomizdat, Moscow, 2008

[2] V. V. Krasheninnikov, Yu. A. Radin and B. I. Shmukler, "About the Validity of Measuring Live Steam and Reheat Steam Temperatures in Starting Power Units, " Therm. eng., Feb. 1990, pp.39-43

[3] RD (Guiding Document) 10-249-98, "Regulations for Strength Design of Stationary Boilers and Steam and Hotwater Pipelines," Nauchno-tekn. Tsentr Bezop. v Promyshl., Gosgortekhnadzor Rosii, 2004

[4] P. Fontaine and J. F. Galopin, "HRSG Optimization for Cycling Duty Based on Euro Norm EN 12952-3," Modern Power systems, Powergen Europe, Madrid, Spain, Oct. 2007 